\title{
OS DESENHOS NA PERSPECTIVA DE UMA ABORDAGEM GEOGRÁFICA: RELATOS DE EXPERIÊNCIA NO PIBID
}

Mateus Vieira de Oliveira1, Universidade Federal de Campina Grande (UFCG/CFP) mateus.agropec22@gmail.com

Ailmo Xavier Soares ${ }^{2}$, Universidade Federal de Campina Grande (UFCG/CFP) ailmoxaviersoares@gmail.com

Cícera Cecilia Esmeraldo Alves ${ }^{3}$ Universidade Federal de Campina Grande (UFCG/CFP) ceciliaesmeraldo@gmail.com

PALAVRAS-CHAVE: geografia; desenhos; PIBID. INTRODUÇÃO

Dentro do escopo da ciência geográfica, utilizam-se algumas categorias de análise, essas categorias são um norte que irá direcionar o pesquisador/professor ou aqueles que tratem da análise dos fenômenos observados no meio. O espaço geográfico, a paisagem, o lugar, o território e a região auxiliam no entendimento das relações e conexões existentes no espaço geográfico, objeto de estudo da Geografia. Portanto, é necessário já nas séries iniciais obter um entendimento de como essas categorias se insere no cotidiano das relações interpessoais e entre o homem e o meio.

O objetivo geral desse trabalho consiste em analisar como os desenhos podem ser trabalhados nas aulas de geografia. Os objetivos específicos são: 1) identificar as potencialidades desse recurso didático no processo de ensino/aprendizagem, 2) promover o ensino de Geografia contextualizado com novas formas de ensinar/aprender.

Sendo de extrema importância alcançar esse conhecimento acerca das categorias geográficas, o PIBID Subprojeto de Geografia, juntamente com a professora supervisora na E.M.E.F.I Cecilia Estolano Meireles, planejamos uma atividade com o recurso didático desenho feito pelos próprios alunos para contextualizar com as categorias da Geografia. Para Santos, (2012, p.195) "Trabalhar com os desenhos é trabalhar com novas formas de ver, compreender as "coisas" e verificar-comprovar as próprias ideias. O indivíduo, quando desenha, expressa uma visão e um raciocínio".

Nessa perspectiva, os desenhos configuram-se como uma forma lúdica e pratica dentro da sala de aula, e é a representação de uma imagem, que possibilita fazer uma contextualização com os conteúdos programáticos nos currículos, e concomitantemente com a 
realidade dos alunos. É importante destacar que cada pessoa constrói os desenhos de acordo com a percepção de mundo que enxerga.

\section{METODOLOGIA}

O presente trabalho foi desenvolvido durante quatro semanas durante as aulas de Geografia no $7^{\mathrm{a}}$ ano A da E.M.E.I.F Cecilia Estolano Meireles em Cajazeiras-PB.

No primeiro encontro fizemos um levantamento dos conhecimentos prévios dos alunos sobre as bases conceituais da disciplina geografia, logo em seguida aplicamos a interversão teórica e metodológica enfatizando as categorias geográficas: paisagem, lugar, território, região e espaço. Para que os alunos/as tivessem uma dimensão dos conceitos da ciência geográfica.

No segundo momento iniciamos a parte prática da oficina, dividindo as equipes para construção de desenhos temáticos que abarcasse as categorias geográficas. Todos foram provocados a construir desenhos que correspondessem as respectivas categorias.

No terceiro encontro demos continuidade a construção dos desenhos, e a confecção de molduras para da maior visibilidade a criatividade dos discentes.

No quarto e último encontro, fizemos uma abordagem teórica sobre a produção dos desenhos em sala de aula, contextualizando com os conteúdos geográficos e a realidade dos discentes. Durante a apresentação dos trabalhos desenvolvidos, a partir das categorias geográficas, os discentes enfatizaram temas pertinentes do seu dia a dia, como por exemplo: o processo de urbanização, a modificação da paisagem no campo e na cidade, a cultura regional e local, os territórios das drogas, problemas socioeconômicos, entre outros.

\section{PANORAMA SOBRE OS DESENHOS}

Ao contextualizar o desenho e Geografia, percebe-se que o aprendizado dos alunos dáse quase de forma espontânea, pois, eles começam a perceber que as categorias geográficas estão conectadas ao dia-a-dia dos mesmos, assim corroborando com Pontuschka, Paganelli e Cacete (2009);

Os desenhos espontâneos, em diferentes faixas etárias e níveis socioeconômicos culturais, possibilitam identificar o desenvolvimento gráfico-espacial dos alunos como representações do mundo próximo e conhecer não só suas informações sobre lugares, mas também seu imaginário sociocultural (PONTUSCHKA, PAGANELLI e CACETE, 2009, pag. 293)

Certamente o desenho é um recurso que estimula o censo critico, desenvolve a capacidade de interpretação, contextualização e análise do aluno, pois, desperta a atenção para 
os fenômenos e objetos da realidade sócio espacial. Sendo assim, é importante destacar a participação de todos na construção dos desenhos e na interpretação dos mesmos, supondo que essa ação favoreceu também o imaginário e a noção do espaço vivido, como bem o senso artístico e cultural de todos.

Nessa oficina, desenvolvida durante o mês junho de 2017, com a referida turma, percebemos através da participação dos alunos/as a importância da valorização dos conhecimentos prévios, e o poder da construção do conhecimento a partir de metodologias simples e fáceis de serem trabalhadas em sala de aula.

\section{CONSIDERAÇÕES FINAIS}

Diante da ação realizada, foi possível contextualizar os conhecimentos geográficos na perspectiva dos desenhos, possibilitando a interação dos alunos, juntamente com os discentes do PIBID e a professora da escola. É importante destacar que através desta atividade os alunos/as tornam-se construtores do saber, uma vez que, ao produzirem seus desenhos apoiados nas categorias geográficas, retratam as múltiplas imagens do imaginário, enfatizando sua realidade de vivência com o espaço geográfico.

Em algumas disciplinas essa atividade é desenvolvida geralmente sem estabelecer uma relação com os conteúdos trabalhados, desconsiderando a riqueza de informações que estes recursos englobam. Apesar de os desenhos serem em sua maioria direcionados para disciplina de artes, estes podem serem trabalhados nos distintos campos dos conhecimentos científicos, em especifico a ciência geográfica que pode e deve desfrutar desse universo mágico.

\section{REFERÊNCIAS}

PONTUSCHKA, Nídia Nacib; PAGANELLI, Tomoko Iyda; CACETE, Núria Hanglei. Para ensinar e aprender Geografia. 3 ed. São Paulo: Cortez, 2009.

SANTOS, Clézio. O uso dos desenhos no ensino Fundamental: Imagens e Conceitos. In: PONTUSCHKA, Nídia Nacib; OLIVEIRA, Ariovaldo Umbelino (Orgs.). Geografia em Perspectiva. 4 ed. São Paulo: Contexto, 2012, pág. 195. 